\title{
First Occurrence of Banana Skipper (Erionota torus) in Kodur Region of Andhra Pradesh, India
}

\author{
D. Srinivasa Reddy ${ }^{{ }^{*}}$ and T. Hemadri ${ }^{2}$ \\ ${ }^{1}$ Entomology, Citrus Research Station, Dr. YSRHU, Tiurpati-517501, AP, India \\ ${ }^{2}$ Entomology, N.S. college of Horticultural Sciences, Affiliated to Dr. YSRHU, Gobburu, \\ 523320, Peddaraveedu, Prakasam District, AP, India \\ *Corresponding author
}

\section{A B S T R A C T}

\section{Keywords}

Skipper, Banana, Grand Naine,

Kodur, Andhra Pradesh

Article Info

Accepted:

10 January 2018 Available Online: 10 February 2018
The hesperiid, Erionota torus Evans (Lepidoptera: Hesperiidae) is reported for the first time on banana crop cv. grand naine from Kodur and Chitvel areas of Kadapa district in Andhra Pradesh as there were no earlier records of occurrence of this pest to that particular areas. The moth prefer to lay eggs in groups and in total five larval instars were observed and some stages had white powder coating on the body with the total life cycle completed in 35- 48 days. The insect pest under observation has causing damage to banana crop to an extent of $8-30 \%$ by making leaf rolls and feeding the entire leaf leaving only midribs depending on the cultivar.

\section{Introduction}

Banana (Musa sp.) is a major fruit crop believed to be originated in South-East Asian and Western pacific regions (Robinson and Sauce, 2010). Among the 470 species of insect and mites damaging banana, only 250 species feed on foliage (Ostmark, 1974). The foliage feeders cause reduction in the photosynthetic area of leaf. In India, slug caterpillars such as Latioa lepida, Miresa decadens, hairy caterpillar, Euproctis sp., Pericalia ricini, leaf beetle Nodostoma subcostatum were recorded as major defoliators by Vevai (1971) and in Andhra Pradesh, so far Spodoptera litura is the major defoliator observed damaging banana crop particularly in this Kodur region.

Erionota species was originally reported from Southeast Asia and widely distributed in Northeast India (Sikkim), Manipur (Prasad and Singh, 1987; Singh, 1997), Andaman and Nicobar Islands (Veenakumari and Mohanraj, 1991), Assam (Deka et al., 1996), Myanmar, Thailand, Laos, Malaysia, China, Vietnam, Taiwan and Singapore. In India, Erinota species was described from Sikkim and is historically known from the Himalaya East and Southeast ward (Raju et al., 2015). Recently i.e. in 2015, Kamala jayanthi et al., 
(2015) noticed that the pest has moved down Southward and has been recorded in South Indian states namely Karnataka, Kerala, Tamilnadu, Maharashtra, Andhra Pradesh and at certain pockets leading to outbreaks mainly in Karnataka and Kerala.

The scientists visited the banana farmer's field in Railway Kodur (Settigunta) and Chitvel mandals of YSR Kadapa district, Andhra Pradesh in November and December months of 2017 and in there we could observe all the four stages of banana skipper (egg, larva, pupa, adult) on Grand Naine cultivar belonging to Dwarf Cavendish group. It has also spread to nearby farmer fields damaging other banana cultivars namely Elakkibale, Sugandhalu and the damage to latter varieties (20-30\%) was higher as compared to former cultivar $(8-12 \%)$.

\section{Probable Mode of spread}

The insect pest has moved from neighbouring Karnataka state to Andhra Pradesh where the farmer has brought banana saplings cv. Grand naine from private company from Bengaluru which may be the probable route of occurrence and infestation. In Kodur region there were no earlier records of occurrence of this pest though the area is well known for banana cultivation and since from ages they are growing four to five varieties of banana namely, Sugandhalu, Rasthali, Nellore Amruthapani, Bontha and Grand Naine.

\section{Biology and life cycle}

The freshly laid eggs observed were pinkish in colour (Fig. 1a) and changed to white before hatching (Fig. 1b). These eggs were laid in group (7-18) on the ventral surface of the leaves and the incubation period was 6-7 days. There were in total five instars that were recorded in the field and the total developmental period took 20-30 days to transform to pupa. Similar larval periods of 23-32 days depending on temperature were recorded by Waterhouse et al., (1998), 25-30 days (Mau et al., 1980) and 20-29 days (Khoo et al., 1991). Pupa was brown in color (Fig. 1h) and the duration it took was 9-11 days, to emerge into adult and in support of our findings, Mau et al., 1980 noticed a 10 days pupal duration and Khoo et al., (1991) also observed the similar pupal duration of 8-12 days.

\section{Nature of damage}

The first instar caterpillars feed on the edges of the leaf and by remaining inside it constructs shelter by rolling the leaf edges and these rolls were many in numbers (11-20) on both the edges of the leaf (Fig. 1d and 2a) and it was also noticed that there was gradual increase in leaf roll size as the caterpillar increased in size (Fig. 2b). It was also seen that the complete defoliation of banana leaf occurs leaving midrib alone in certain orchard leading to severe damage (Fig. 2c).

One observation noted was that the caterpillars body of later instars was totally covered with a white powdery substance (Fig. 1f) as compared to early instars larvae (Fig. 1e). The growth of this white powdery substance is believed to be a by-product of metabolism (Waterhouse et al., 1998).

The insect pest under worry if not managed at the right time using integrated practices may lead to serious damage to banana cultivation in the region threatening both the local cultivars and also commercial varieties affecting the production and even as per the preliminary observations, it has huge impact for small and marginal banana growers who cultivate certain varieties exclusively for leaf purpose used as meal plates that are sold to nearby markets viz., Chennai, Nellore, Tirupati. 
Fig. 1 Banana skipper life stages observed in Kodur region of Andhra Pradesh on Grand Naine. freshly laid pinkish eggs (a); white eggs before hatching (b); Neonate larva (c); banana leaf rolls (d); early instar larvae without mealycover (e); late instar larvae with mealycover (f); pupa without mealycover (g); Pupa with mealycover (h); E. torus adult (i)
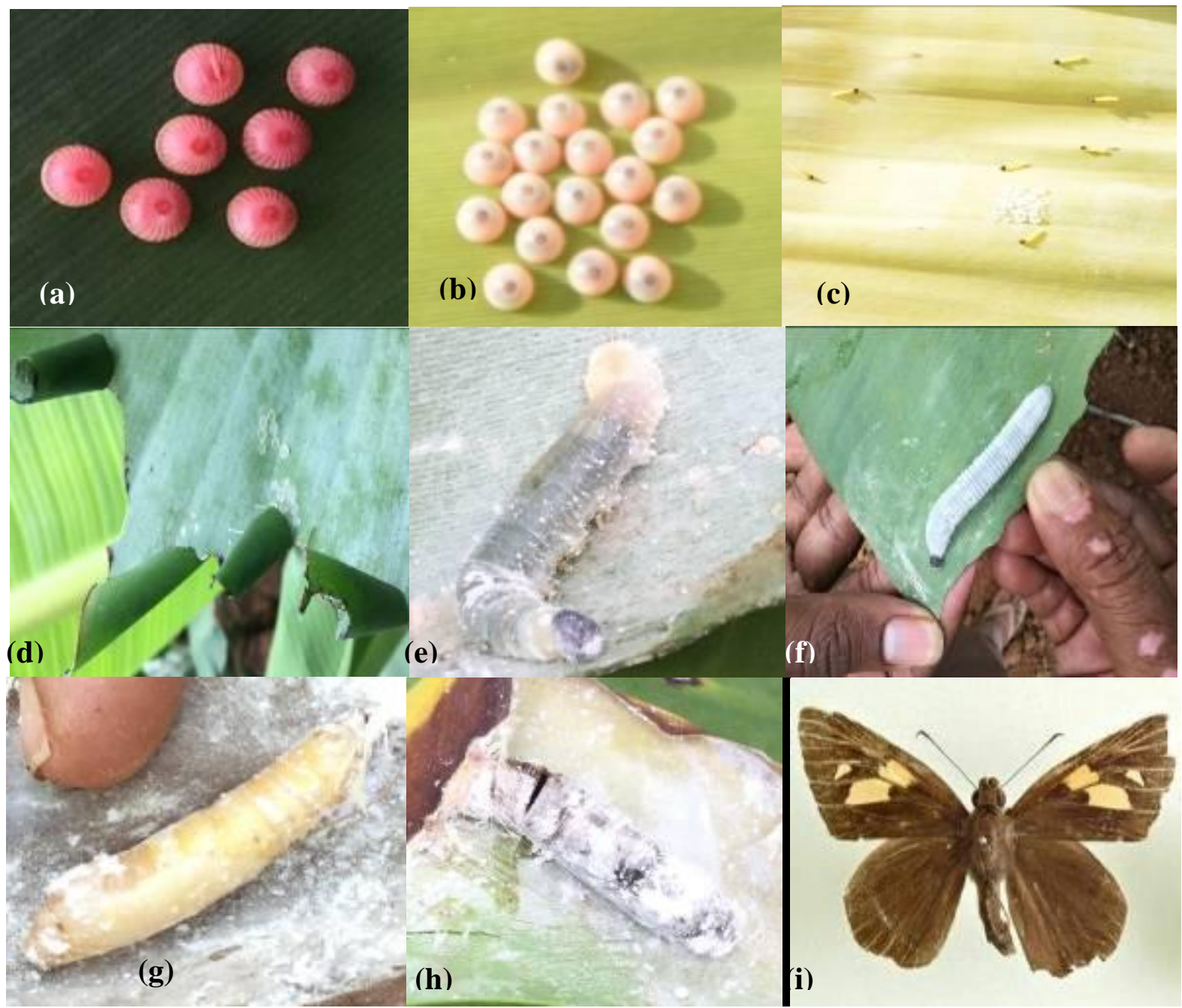

Fig. 2 Banana skipper damage symptoms observed in Railway Kodur region of Andhra Pradesh on Grand Naine. Banana leaf rolls at leaf edge (a); cylindrical leaf roll (b); Heavily defoliated banana leaf (c)

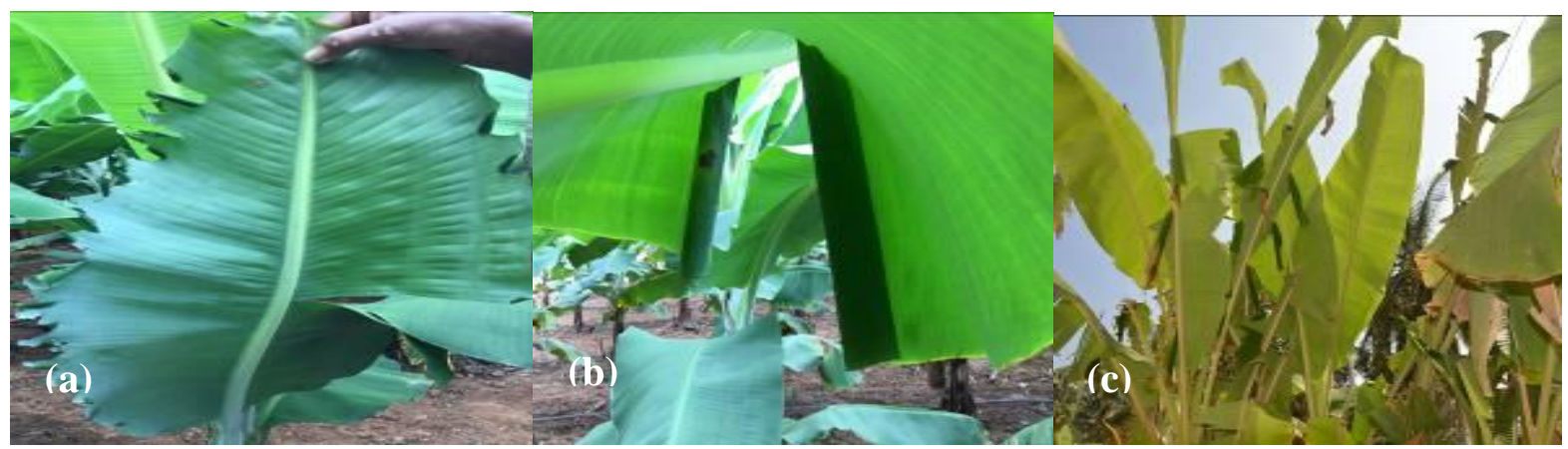




\section{References}

Deka, K. C., S. K. Dutta and Goswami, M. M. 1996. Preliminary observations on Erionota thrax Linn. (Lepidoptera, Hesperiidae): a potential pest of banana in North East India. Insect Environment. 2 (1): 11.

Kamala jayanthi, P. D., P. V. Rami reddy, Vivek Kempraj and Shashank. 2015. Outbreak of banana skipper, Erionota torus Evans (Lepidoptera: Hesperiidae) in southern India: Evidence of expanded geographic range. Pest Management in Horticultural Ecosystems. 21 (1): 95-97.

Khoo, K. C., P. A. C. Ooi and Ho, C. T. 1991. Crop pests and their Management in Malaysia, Tropical Press Sdn. Bhd, Malaysia, $233 \mathrm{pp}$.

Mau, R. F. L., K. Murai, B. Kumashiro and Teramoto, K. 1980. Biological control of the banana skipper, Pelopidas thrax (Linnaeus), (Lepidoptera: Hesperiidae) in Hawaii. Proceedings of the Hawaiian Entomological society. 23 (2): 231-238.

Ostmark, H. E. 1974. Economic Insect pests of banana. Annual Review of Entomology. 19:161-176.

Prasad, B., and Singh, O. L. 1987. Insect pests of banana and their incidence in Manipur. Indian Journal of Hill
Farming. 1 (1): 71-73.

Raju, D., K. Kunte, S. Kalesh, Manoj, P., H. Ogale and Sanap, R. 2015. Erionota torus Evans, 1941 - Rounded Palmredeye. Kunte, K., P. Roy, S. Kalesh and U. Kodandaramaiah (eds.). Butterflies of India, v. 2.20. Indian Foundation for Butterflies.

Robinson, J. C., and Sauce, V. G. 2010. Bananas and Plantains 2nd Ed. CAB International. Pp.312.

Singh, M. P. 1997. Erionata thrax Linn, a serious pest of banana in Manipur and its potential biocontrol agent, Brachymeria euploeae (West). Insect Environment. 3 (2): 51-52.

Veenakumari, K., and Mohanraj, P. 1991. Erionota thrax L. (Lepidoptera: Hesperiidae), a new record to Andaman Islands. Journal of Andaman Sciences Association. 7 (2): 91-92.

Vevai, E. J. 1971. Know your crop, its pest problems and control. Pesticides. 5 (6): 38-56.

Waterhouse, D. F., and Birribi, D., David, V.1998. Economic benefits to pupa New Guinea and Australia from biological control of banana skipper (Erionota thrax). CSIRO Division of Entomology, Australia, 36 pp.

\section{How to cite this article:}

Srinivasa Reddy, D. and Hemadri, T. 2018. First Occurrence of Banana Skipper (Erionota torus) in Kodur Region of Andhra Pradesh. Int.J.Curr.Microbiol.App.Sci. 7(02): 1081-1084. doi: https://doi.org/10.20546/ijcmas.2018.702.134 